\title{
Correlation between microsatellite instability and RAS gene mutation and stage III colorectal cancer
}

\author{
WENBO NIU ${ }^{1}$, GUIYING WANG ${ }^{1}$, JUN FENG $^{1}$, ZHENG LI $^{1}$, CHENHUI LI $^{1}$ and BAOEN SHAN ${ }^{2}$ \\ ${ }^{1}$ Department of Surgery II and ${ }^{2}$ Center of Scientific Research, \\ The Fourth Hospital of Hebei Medical University, Shijiazhuang, Hebei 050000, P.R. China
}

Received May 21, 2018; Accepted September 25, 2018

DOI: $10.3892 / \mathrm{ol} .2018 .9611$

\begin{abstract}
Correlation between RAS gene mutation and microsatellite instability (MSI) status in cancer tissues and clinicopathological parameters of patients with stage III colorectal cancer (CRC) were investigated. Tissues were collected from 180 patients diagnosed with stage III CRC in the Department of Gastrointestinal Surgery of the Fourth Hospital of Hebei Medical University from 2012 to 2016. RAS gene mutations in paraffin sections were detected by PCR and Sanger sequencing. Expression of mismatch repair proteins MLH1, MSH2, MSH6 and PMS2 was detected by immunohistochemistry, and MSI status was determined based on the positive and negative expression combinations of the above proteins, and the correlation with clinicopathological parameters of CRC was analyzed. Mutation rates of KRAS and NRAS were $48.33 \%(87 / 180)$ and $2.78 \%$ (5/180), respectively. Mutation rate of p.G12D in codon 12 of exon 2 in KRAS gene was the highest $(31 / 87,35.63 \%)$. Mutation rate of p.G12D in codon 12 of exon 2 in NRAS gene was the highest $(2 / 5,40 \%)$. Mutation rate of KRAS gene in right colon was higher than that in left colon and rectum $(\mathrm{p}<0.05)$, and mutation rate in $\mathrm{N} 2 \mathrm{~b}$ phase was higher than that in $\mathrm{N} 2 \mathrm{a}$ and $\mathrm{N} 1$ phases $(\mathrm{p}<0.01)$. In low degree of microsatellite instability (MSI-L) and high degree of microsatellite instability (MSI-H) status, negative MKH1 protein expression was dominant (18/32, $56.25 \%$ ). MSI-H in CRC patients aged $\geq 50$ years was higher than that of CRC patients $<50$ years. Rates of MSI-H in N1, $\mathrm{N} 2 \mathrm{a}$, and $\mathrm{N} 2 \mathrm{~b}$ were $1.75,12.82$, and $1.11 \%(\mathrm{p}<0.05)$. Mutation rate of KRAS gene in MSI-H status of stage III CRC patients was significantly higher than that in MSI-L/microsatellite stability (MSS) $(\mathrm{p}<0.05)$. Mutation of RAS gene and the status of MSI are involved in the occurrence and development of
\end{abstract}

Correspondence to: Dr Baoen Shan, Center of Scientific Research, The Fourth Hospital of Hebei Medical University, 12 Health Road, Shijiazhuang, Hebei 050000, P.R. China

E-mail:sh623t@163.com

Key words: stage III colorectal cancer, RAS gene, microsatellite instability, mismatch repair protein stage III CRC. Detection of $R A S$ gene has important significance for the individual treatment of $\mathrm{CRC}$ in clinic.

\section{Introduction}

Colorectal cancer (CRC) is one of the most common malignant tumors of the digestive tract in the world, and it is seriously endangering the health of humans. In recent years, the incidence of CRC showed an increasing trend and onset age is becoming increasingly younger (1). At present, surgical resection is the main treatment of CRC (2). However, due to differences in genotypes among different individuals, the incidence of drug resistance during chemotherapy increases significantly (3). Therefore, how to achieve personalized treatment of CRC under the guidance of precision medical treatment has been the focus of treatment in recent years.

Studies have shown that changes in molecular pathways are involved in the development of CRC tumors, of which microsatellite instability (MSI) and chromosomal instability (CIN) play the most important roles (4). MSI is the change of DNA genome sequence caused by mismatch repair gene mutation during DNA replication. It plays an important role in the regulation of various tumors, and CRC is one of the malignant tumors with a high incidence of MSI (5). It has been reported that $>90 \%$ of CRCs have a high degree of MSI (6). CIN is related to a variety of signal transduction pathways, of which the epidermal growth factor receptor (EGFR)-mediated signaling pathway plays an important role (7). Activation of the EGFR signal transduction pathway can regulate the phosphorylation of downstream signaling pathways, thereby promoting cell proliferation (8). $R A S$ proto-oncogene family includes $K R A S, H R A S$, and $N R A S$, of which the KRAS gene has the highest mutation rate in CRC disease and can be as high as $45 \%$ (9). KRAS is an important component of the downstream pathway of the EGFR signaling pathway, and its mutation can lead to activation of the RAS/RAF/MAPK signaling pathway and loss of EGFR regulation (10). Therefore, outcomes of clinical use of EGFR drugs targeting KRAS gene mutations in CRC patients are extremely poor. In this study, PCR-Sanger sequencing and immunohistochemical methods were used to detect RAS gene mutations and MSI status in paraffin sections of patients with stage III CRC and to analyze the correlation with clinical parameters. Our study provided theoretical basis for personalized treatment for clinical CRC. 
Table I. RAS gene amplification primer sequences and PCR product length.

\begin{tabular}{lllr}
\hline Name & \multicolumn{1}{c}{ Forward primer } & \multicolumn{1}{c}{ Reverse primer } & Fragment length (bp) \\
\hline KRAS & & & 92 \\
Exon 2 & CCAGACTGTGTTTCTCCCTTC & TTTAAACCCACCTATAATGGTG & 131 \\
Exon 3 & CTTGGATATTCTCGACACAGCA & TCCCTCATTGCACTGTACTCCT & 120 \\
Exon 4 & TGATTTTCAGAAAACAGAT & GACACAAAACAGGCTCAGGA & 128 \\
NRAS & & & 97 \\
Exon 2 & ATGACTGAGTACAAACTGGTC & CTCTATGGTGGGATCATATTG & 93 \\
Exon 3 & AAACAAGTGGTTATAGATGGT & CACAGAGGAAGCCTTCGCCT & 204 \\
Exon 4 & TTGGCCCCATTTAGAAACTTCTGT & TCATCTTGGGCTCTTGTGCCA & \\
HRAS & & & \\
Exon 2 & TCACGCACCAACGTGTAGAA & CTTCGAGATGGCCAGAGTCC & 2 \\
\hline
\end{tabular}

\section{Patients and methods}

Patient data. Tissues were collected from 180 patients who were diagnosed as stage III CRC in the Department of Gastrointestinal Surgery of the Fourth Hospital of Hebei Medical University (Shijiazhuang, China). All tissue specimens were fixed with $10 \%$ formaldehyde and stored as paraffin blocks. These patients included 104 males (57.78\%) and 76 females (42.22\%), and age ranged from 26 to 81 years, with an average age of $54.38+17.32$ years. Inclusion criteria: i) all patients were treated with surgery and excluded from chemotherapy, radiotherapy, biological therapy, and other special treatment methods; ii) patients pathologically diagnosed with stage III CRC; iii) excluded from other intestinal diseases or other parts of the original tumor; and iv) all the patients and their families were informed, and signed informed consent. In this study, the clinical and pathological grade of tumors were determined according to the standards proposed by the Union for International Cancer Control (UICC) in 2010 (11).

The study was approved by the Ethics Committee of the Fourth Hospital of Hebei Medical University. Signed informed consents were obtained from the patients or the guardians.

Detection of gene mutation. DNA was extracted from CRC paraffin blocks using a DNA FFPE Tissue kit (Thermo Fisher Scientific, Inc., Waltham, MA, USA) according to the manufacturer's instructions. PCR (Thermo Fisher Scientific, Inc.) reactions were performed to amplify DNA. All primer sequences are listed in Table I. Primers were synthesized by Sangon Biotech Co., Ltd. (Shanghai, China). PCR reaction conditions were: $95^{\circ} \mathrm{C}$ for $10 \mathrm{~min}$, followed by 40 cycles of $95^{\circ} \mathrm{C}$ for $30 \mathrm{sec}, 50^{\circ} \mathrm{C}$ for $30 \mathrm{sec}$ and $70^{\circ} \mathrm{C}$ for $1 \mathrm{~min}$, and $70^{\circ} \mathrm{C}$ for $10 \mathrm{~min}$. After purification of PCR products, Sanger sequencing of KRAS, NRAS and HRAS in the RAS family was performed using the ABI 3730xl sequencer (Sangon Biotech Co., Ltd.), and the sequencing results were analyzed.

Immunohistochemistry. Immunohistochemistry was used to detect the expression of MLH1, MSH2, MSH6 and PMS2. CRC tissue blocks were used to prepare tissue sections with a thickness of $4 \mu \mathrm{m}$, which were fixed on glass slide, and then baked at $65^{\circ} \mathrm{C}$ for $2 \mathrm{~h}$. After dewaxing and hydration, immunohistochemical SP was performed. All antibodies were purchased from Santa Cruz Biotechnology, Inc. (Santa Cruz, CA, USA). Tissue sections were incubated with primary mouse anti-human MLH1 (dilution, 1:200; cat. no. sc-56160), MSH2 (dilution, 1:250; cat. no. sc-56163), MSH6 (dilution, 1:100; cat. no. 137015), and PMS2 (dilution, 1:300; cat. no. sc-137015) monoclonal antibodies overnight at $4^{\circ} \mathrm{C}$, followed by incubation with goat anti-mouse secondary polyclonal antibody (dilution, 1:100; cat. no. sc-2005) at $37^{\circ} \mathrm{C}$ for $1 \mathrm{~h}$. DAB color development and hematoxylin counterstaining were performed. PBS was used instead of the primary antibody to serve as a negative control. Positive sections were used as positive controls.

Determination of the results. Six visual fields were randomly selected under a 400-fold microscope (Olympus, Tokyo, Japan), and the results were judged by percentage of positive cells and depth of coloration. i) Scoring according to depth of coloration: negative was 0 points, light yellow was 1 point, brown-yellow score was 2 points, and brown score was 3 points. ii) Scoring according to the percentage of positive cells: $0-30 \%$ was 1 point, $30-70 \%$ was 2 points, and $70-100 \%$ was 3 points. Product of the two scores $\geq 3$ points was positive, otherwise it was negative. MSI result was determined as: positive expression of the above four proteins in CRC patients was defined as microsatellite stability (MSS). Negative expression of one of the proteins was defined as low degree of microsatellite instability (MSI-L). The presence of negative expression of two or more proteins was defined as high degree of microsatellite instability (MSI-H) (12).

Statistical analysis. Statistical analysis was performed using the SPSS 22.0 statistical analysis software (IBM Corp., Armonk, NY, USA). Measurement data was recorded as mean \pm SD Count data were recorded as rates and processed using Chi-square test to investigate the relationship between RAS gene mutations, MSI status, and CRC clinicopathological parameters. $\mathrm{P}<0.05$ indicates a difference with statistical significance (Table I).

\section{Results}

RAS gene mutation in stage III CRC patients. Analysis of 180 cases of phase III CRC tissues revealed that RAS mutation 

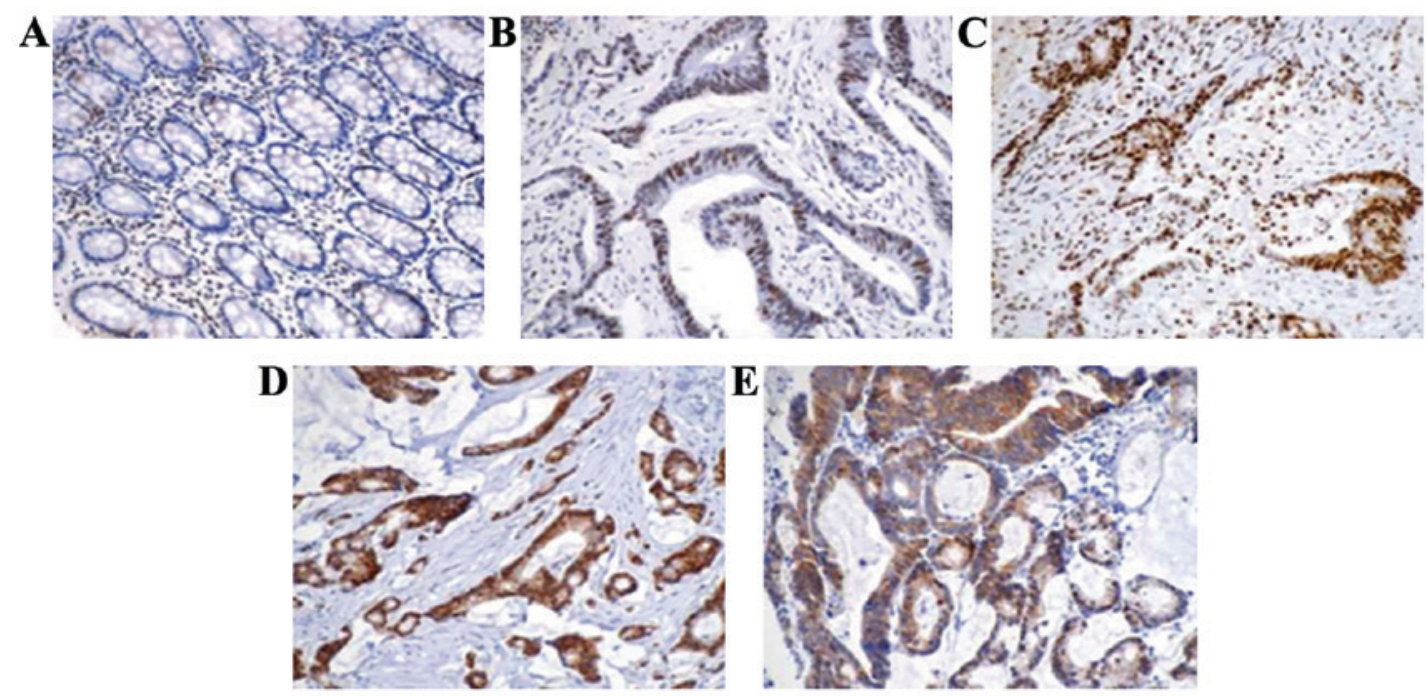

Figure 1. Detection of MSI status in stage III CRC patients by immunohistochemistry (SP method, x100). (A) Negative control group; (B) MLH1 positive expression; (C) MSH2 positive expression; (D) MSH6 positive expression; (E) PMS2 positive expression. MSI, microsatellite instability; CRC, colorectal cancer.

rate was $51.11 \%(92 / 180)$, of which KRAS and NRAS gene mutation rates were $48.33 \%(87 / 180)$ and $2.78 \%(5 / 180)$, respectively. HRAS mutation was not detected. The number of exon 2, 3 and 4 mutations in KRAS gene was 78 (89.66\%), 2 (2.30\%), and $7(8.05 \%)$, respectively. Mutation rate of p.G12D in codon 12 of exon 2 in KRAS gene was the highest (31/87, $35.63 \%$ ). Mutation rate of p.G12D in codon 12 of exon 2 in NRAS gene was the highest $(2 / 5,40 \%)$ (Table II).

MSI status of patients with stage III CRC. Immunohistochemical detection of 180 cases of CRC tissues revealed that MLH1 protein positive expression was observed in 168 cases (93.33\%) and negative expression in 12 cases (6.67\%). MSH2 protein positive expression was observed in 154 cases $(85.56 \%)$, and negative expression in 26 cases (14.44\%). MSH6 protein was positively expressed in 151 cases $(83.89 \%)$ and negatively expressed in 29 cases $(16.11 \%)$. PMS 2 protein was positively expressed in 148 cases $(82.22 \%)$ and negatively expressed in 32 cases $(17.78 \%)$. There were 148 cases of MSS status (82.22\%), 22 cases of MSI-L status (12.22\%), and 10 cases of MSI-H status (5.56\%). In MSI-L and MSI-H status, MLH1 protein negative expression was the dominant $(18 / 32,56.25 \%)$. Fig. 1 shows the immunohistochemical staining of MSS.

Relationship between RAS gene mutation and clinicopathological parameters of patients with stage III CRC. This study investigated the relationship between RAS gene mutations and clinicopathological parameters in stage III CRC patients and found that the mutation rate of KRAS gene in the right colon was $65.82 \%$, which was significantly higher than that of the left colon and rectum $(\mathrm{p}<0.05)$. Mutation rate in $\mathrm{N} 2 \mathrm{~b}$ phase was $81.48 \%$, which was significantly higher than that in $\mathrm{N} 2 \mathrm{a}$ and $\mathrm{N} 1$ phases $(\mathrm{p}<0.01)$. NRAS gene mutation was not correlated with age, sex, lymph node metastasis, tumor site, depth of invasion, or pathological stage of CRC patients ( $>0.05)$ (Table III).

Relationship between MSI status and clinicopathological parameters of patients with stage III CRC. This study
Table II. Incidence of KRAS and NRAS mutations [n (\%)].

\begin{tabular}{lcc}
\hline Gene exon & Gene mutations & $\mathrm{n}(\%)$ \\
\hline KRAS & & \\
Exon 2 & p.G12D & $31(35.63)$ \\
& p.G12V & $14(16.09)$ \\
& p.G12A & $5(5.75)$ \\
& p.G12C & $4(4.60)$ \\
Exon 3 & p.G12S & $4(4.60)$ \\
& p.G13D & $1(1.15)$ \\
Exon 4 & p.A59T & $19(21.84)$ \\
& p.Q61H & $1(1.15)$ \\
Total & p.A146T & $1(1.15)$ \\
NRAS & p.A146V & $4(4.60)$ \\
Exon 2 & Others & $1(1.15)$ \\
Exon 3 & & $2(2.30)$ \\
& & $87(48.33)$ \\
Total & p.G12D & \\
& p.A18T & $2(40.00)$ \\
& p.Q61L & $1(20.00)$ \\
& & $1(20.00)$ \\
& & $1(20.00)$ \\
& & $5(2.78)$ \\
& &
\end{tabular}

investigated the relationship between MSI status and clinicopathological parameters of patients with stage III CRC. Results showed that MSI-H was observed in 9 cases $(6.82 \%)$ in patients with $\geq 50$ years of age, which was significantly higher than that of CRC patients $<50$ years ( 1 case, $2.08 \%, \mathrm{p}<0.05$ ). The ratios of MSI-H in N1, N2a, and N2b phases were 1.75, 12.82 , and $1.11 \%$, respectively, and significant differences were found among them $(\mathrm{p}<0.05)$ (Table IV).

Correlation between MSI status and RAS gene mutation in stage III CRC patients. Results of this study revealed that 


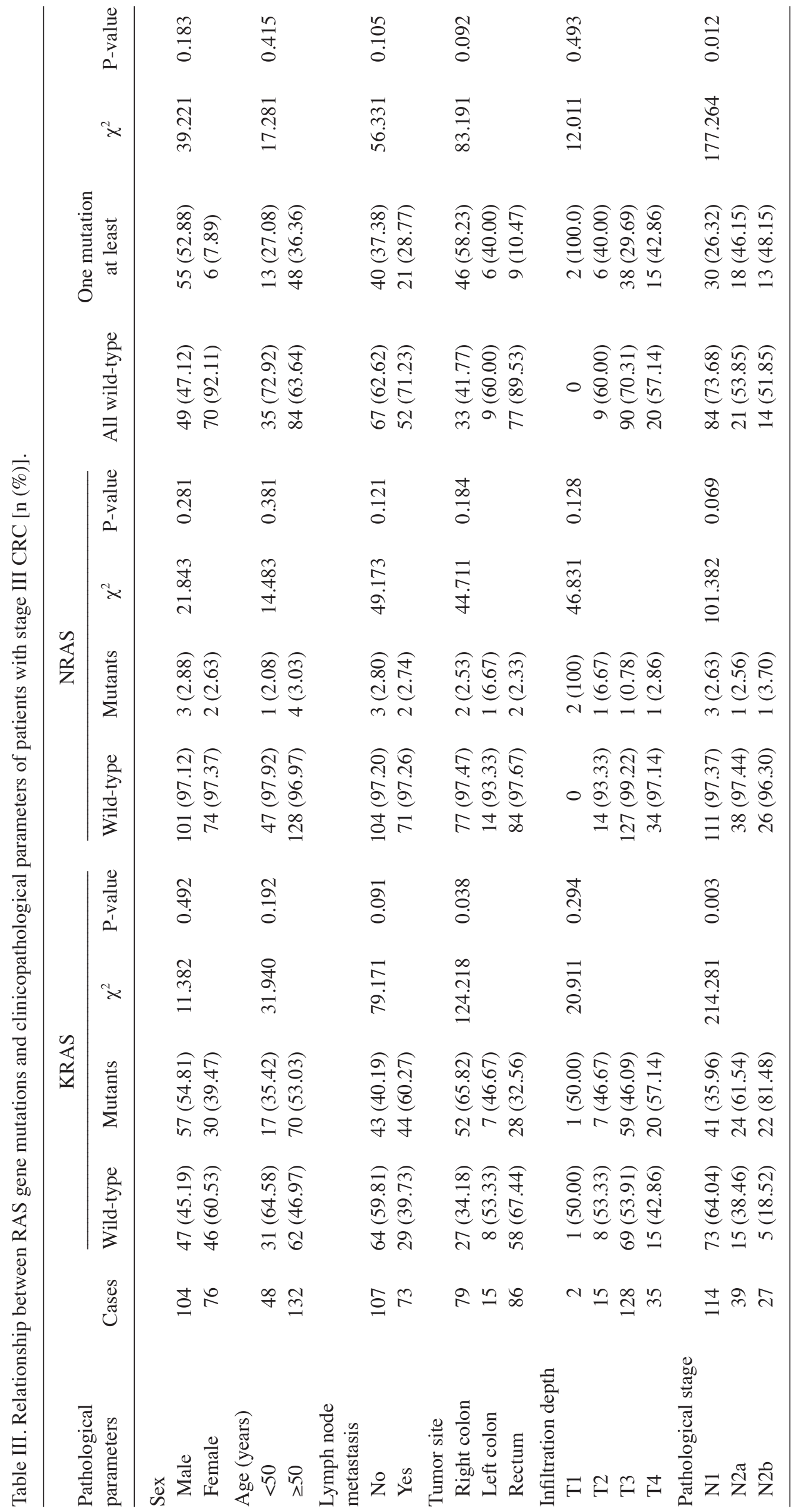


Table IV. Relationship between MSI status and clinicopathological parameters of patients with stage III CRC [n (\%)].

\begin{tabular}{|c|c|c|c|c|c|}
\hline Pathological parameters & Cases & MSI-H & MSI-L/MSS & $\chi^{2}$ & P-value \\
\hline \multicolumn{6}{|l|}{ Sex } \\
\hline Male & 104 & $7(6.73)$ & $97(93.27)$ & 13.281 & 0.381 \\
\hline Female & 76 & $3(3.95)$ & $73(96.05)$ & & \\
\hline \multicolumn{6}{|l|}{ Age (years) } \\
\hline$<50$ & 48 & $1(2.08)$ & $47(97.92)$ & 71.306 & 0.028 \\
\hline$\geq 50$ & 132 & $9(6.82)$ & $123(93.18)$ & & \\
\hline \multicolumn{6}{|l|}{ Lymph node metastasis } \\
\hline No & 107 & $6(5.61)$ & $101(94.39)$ & 41.811 & 0.128 \\
\hline Yes & 73 & $4(5.48)$ & $69(94.52)$ & & \\
\hline \multicolumn{6}{|l|}{ Tumor site } \\
\hline Right colon & 79 & $7(8.86)$ & $72(91.14)$ & 59.441 & 0.091 \\
\hline Left colon & 15 & $1(6.67)$ & $14(93.33)$ & & \\
\hline Rectum & 86 & $2(2.33)$ & $84(97.67)$ & & \\
\hline \multicolumn{6}{|l|}{ Infiltration depth } \\
\hline $\mathrm{T} 1$ & 2 & 0 & $2(100.0)$ & 32.912 & 0.294 \\
\hline $\mathrm{T} 2$ & 15 & $1(6.67)$ & $14(93.33)$ & & \\
\hline $\mathrm{T} 3$ & 128 & $7(5.47)$ & $121(94.53)$ & & \\
\hline $\mathrm{T} 4$ & 35 & $2(5.71)$ & 33 (94.29) & & \\
\hline \multicolumn{6}{|l|}{ Pathological stage } \\
\hline $\mathrm{N} 1$ & 114 & $2(1.75)$ & $112(98.25)$ & 101.221 & 0.012 \\
\hline $\mathrm{N} 2 \mathrm{a}$ & 39 & $5(12.82)$ & 34 (87.18) & & \\
\hline $\mathrm{N} 2 \mathrm{~b}$ & 27 & $3(1.11)$ & $24(88.89)$ & & \\
\hline
\end{tabular}

MSI, microsatellite instability; CRC, colorectal cancer; MSI-H, high degree of microsatellite instability; MSI-L, low degree of microsatellite instability; MSS, microsatellite stability.

Table V. Correlation between MSI status and RAS gene mutation in patients with stage III CRC [n (\%)].

\begin{tabular}{|c|c|c|c|c|c|c|c|c|c|}
\hline \multirow[b]{2}{*}{ MSI status } & \multirow[b]{2}{*}{ Cases } & \multicolumn{4}{|c|}{ KRAS } & \multicolumn{4}{|c|}{ NRAS } \\
\hline & & Wild-type & Mutants & $\chi^{2}$ & P-value & Wild-type & Mutants & $\chi^{2}$ & P-value \\
\hline MSI-H & 10 & $4(40.00)$ & $6(60.00)$ & 104.281 & 0.011 & $9(90.00)$ & $1(1.00)$ & 14.921 & 0.385 \\
\hline MSI-L/MSS & 170 & $89(52.35)$ & $81(47.65)$ & & & $166(97.65)$ & $4(2.35)$ & & \\
\hline
\end{tabular}

MSI, microsatellite instability; CRC, colorectal cancer; MSI-H, high degree of microsatellite instability; MSI-L, low degree of microsatellite instability; MSS, microsatellite stability.

mutation rate of $K R A S$ gene in MSI-H status of stage III CRC patients was $60 \%(6 / 10)$, which was significantly higher than that in MSI-L/MSS $(47.65 \%, 81 / 170, \mathrm{p}<0.05)$. However, there was no significant difference in NRAS gene mutation rate among MSI-H, MSI-L/MSS status ( $\mathrm{p}>0.05$ ) (Table V).

\section{Discussion}

CRCs lack obvious symptoms and most patients are diagnosed with tumor metastasis, which is a major challenge of clinical treatment. Realization of disease molecular typing in individuals with tumors can help identify the biological characteristics of the tumor and clarify its pathogenesis (13).
The three main molecular properties of CRC are CIN, MSI and $\mathrm{CpG}$ island methylation (14). The most important EGFR signal transduction pathway in CIN plays an important role in malignant transformation of tumors. Studies have shown that high expression of level EGFR in tumor tissue of malignant tumors promotes tumor cell invasion and metastasis (15). $K R A S, N R A S$ and HRAS genes in RAS family are important downstream components of the EGFR signaling pathway. Studies have shown that mutations in KRAS gene cause conformational changes in KRAS protein that reduce its ability to bind to GDP. The binding of KRAS protein to GDP activates KRAS protein, ultimately activating downstream proliferative signaling pathways and promoting tumor cell 
growth (16). Therefore, the 2010 NCCN guidelines clearly stated that CRC patients should be tested for KRAS gene mutation rates to guide the clinical application of anti-EGFR signaling pathway drugs (17). MSI is another molecular characteristic of CRC, and its detection has become increasingly popular in the diagnosis of CRC. Mismatch repair genes encode MLH1, MSH2, PMS2, and MSH6 proteins to identify replication errors during DNA replication. DNA polymerases cleave the erroneously-replicated fragments, and DNA ligases cleave both ends of the excised fragments, so as to achieve correct DNA replication (18). Microsatellites are small DNA fragments in the human genome. Microsatellites are repeated sequences and error rate is high during replication. However, when the mismatch repair gene is mutated, the encoded protein cannot be expressed, and DNA erroneous replication cannot be corrected, eventually resulting in the production of MSI (19). Therefore, this study explored the correlation between RAS gene mutations, MSI status and the occurrence and development of CRC, so as to provide theoretical basis for individualized treatment of CRC patients.

In this study, tissue paraffin specimens from 180 patients with stage III CRC were examined. Results showed that the RAS mutation rate was 51.11\% (92/180) and KRAS and NRAS gene mutation rate was $48.33 \%(87 / 180)$ and $2.78 \%(5 / 180)$, respectively. It has been reported that KRAS gene mutation rate in CRC patients is 35-45\% (20), which is generally consistent with the results of our study. Ye et al (21) investigated the CRC of Chinese population and found that the mutation rate of KRAS gene was $37.9 \%$, which was slightly lower than the results of our study. The possible explanation is they only included the 12 th codon. In this study, codons 12 and 13 in exon 2 were both detected. Results showed that the number of exon 2, 3 and 4 mutations in KRAS mutations was 78 cases $(89.66 \%), 2$ cases $(2.30 \%), 7$ cases $(8.05 \%)$, respectively. Mutation rate of p.G12D in codon 12 of exon 2 was the highest $(35.63 \%, 31 / 87)$, which was in agreement with that reported by Ye et al (21). Mutation rate of p.G13D in codon 13 was $21.84 \%$ (19/87), which was lower than the mutation rate of codon 12 . This result is consistent with that of Omidifar et al (22). HRAS mutation was not detected, which was consistent with the results of previous studies (23). This study further analyzed the correlation between KRAS and NRAS mutations and the clinicopathological parameters of phase III CRC and found that mutation rate of KRAS gene in right colon was $65.82 \%$, which was significantly higher than that in left colon and rectum $(\mathrm{p}<0.05)$. Mutation rate in $\mathrm{N} 2 \mathrm{~b}$ phase was $81.48 \%$, which was significantly higher than that in N2a and N1 phases ( $<<0.01)$, but there was no correlation with other pathological parameters. Studies have shown that the age of patients with KRAS and CRC and the degree of tumor differentiation are closely observed $(24,25)$. An explanation of the different results may be the differences in the survey population. It has been reported that NRAS gene mutations are associated with low expression of c-MET, and NRAS gene mutations are more likely to occur in elderly patients with malignant melanoma (26). In this study we found that NRAS gene mutations were not associated with age, sex, lymph node metastasis, tumor location, depth of invasion, and pathological stage of patients with CRC, possibly due to the fact that mutation rate of NRAS in CRC is significantly lower than that of KRAS (27). In addition, the sample size of our study was small and biased results cannot be avoided.

In this study, immunohistochemistry was used to detect phase III CRC tissue paraffin sections. There were 148 cases (82.22\%) of MSS status, 22 cases $(12.22 \%)$ of MSI-L status, 10 cases $(5.56 \%)$ of MSI-H status, and MKH1 protein negative expression was dominant in MSI-L and MSI-H status $(18 / 32,56.25 \%)$, indicating that patients with stage III CRC are mainly MSS. Fleming et al (28) analyzed 128 patients with malignant rectal cancer and found that patients with MSI-H mostly showed poor differentiation, lymph node infiltration, and high degree of tissue heterogeneity, and MSI-H mostly occurred in female patients and right semi-colon. Correlation analysis showed that MSI-H is closely related to the pathological stage of CRC, and it mostly occurs in elderly patients aged $\geq 50$ years. The reason for the discrepancy in the analysis is that this study only selected patients with stage III CRC as the study subjects, and Fleming et al (28) selected patients with stage II and III CRC as study subjects. Finally, the relationship between RAS gene mutation and MSI was analyzed. It was found that the mutation rate of $K R A S$ gene in MSI-H status of stage III CRC patients was $60 \%(6 / 10)$, which was significantly higher than that in MSI-L/MSS $(47.65 \%, 81 / 170)$. Mutation rate of NRAS gene was not correlated with MSI. Ogura et al (26) found that patients with MSI-L tumors were more likely to have NRAS mutations than KRAS mutations, possibly due to the different subjects included in that study.

In summary, RAS gene mutation and MSI status are involved in the occurrence and development of stage III CRC, and detection of these indexes is of great significance to the individual treatment of $\mathrm{CRC}$ in the clinic.

\section{Acknowledgements}

Not applicable.

\section{Funding}

No funding was received.

\section{Availability of data and materials}

The datasets used and/or analyzed during the present study are available from the corresponding author on reasonable request.

\section{Authors' contributions}

WN drafted the manuscript. WN and GW were mainly devoted to collecting and interpreting the general data. JF and ZL detected gene mutation. CL and BS were responsible for immunohistochemistry. All authors read and approved the final manuscript.

\section{Ethics approval and consent to participate}

The study was approved by the Ethics Committee of the Fourth Hospital of Hebei Medical University (Shijiazhuang, China). Signed informed consents were obtained from the patients or the guardians. 


\section{Patient consent for publication}

Not applicable.

\section{Competing interests}

The authors declare that they have no competing interests.

\section{References}

1. Martins C, Sousa P, Araújo T, Castro-Poças F and Pedroto I: Mediastinal mass in a patient with colorectal cancer: A diagnostic challenge. GE Port J Gastroenterol 24: 193-197, 2017.

2. Cermak K, Thill V, Simoens CH, Smets D, Ngongang CH and da Costa PM: Surgical resection for colon cancer: laparoscopic assisted vs. open colectomy. Hepatogastroenterology 55: 412-417, 2008 .

3. Heo JH, Ryu CG, Jung EJ, Paik JH and Hwang DY: Clinical significance of preoperative virtual colonoscopy for evaluation of the proximal colon in patient with obstructive colorectal cancer. Ann Coloproctol 33: 130-133, 2017.

4. Wicha MS: Targeting self-renewal, an Achilles' heel of cancer stem cells. Nat Med 20: 14-15, 2014.

5. Jiricny J: The multifaceted mismatch-repair system. Nat Rev Mol Cell Biol 7: 335-346, 2006.

6. Iyer RR, Pluciennik A, Burdett V and Modrich PL: DNA mismatch repair: Functions and mechanisms. Chem Rev 106: 302-323, 2006

7. Barberán $\mathrm{S}$, Fraguas $\mathrm{S}$ and Cebrià $\mathrm{F}$ : The EGFR signaling pathway controls gut progenitor differentiation during planarian regeneration and homeostasis. Development 143: 2089-2102, 2016.

8. Saafan H, Foerster S, Parra-Guillen ZP, Hammer E, Michaelis M, Cinatl J Jr, Völker U, Fröhlich H, Kloft C and Ritter CA: Utilising the EGFR interactome to identify mechanisms of drug resistance in non-small cell lung cancer - proof of concept towards a systems pharmacology approach. Eur J Pharm Sci 94: 20-32, 2016.

9. Tang Y, Zhou H, Chen A, Pittman RN and Field J: The Akt proto-oncogene links Ras to Pak and cell survival signals. J Biol Chem 275: 9106-9109, 2000.

10. Di Nicolantonio F, Martini M, Molinari F, Sartore-Bianchi A, Arena S, Saletti P, De Dosso S, Mazzucchelli L, Frattini M, Siena S, et al: Wild-type BRAF is required for response to panitumumab or cetuximab in metastatic colorectal cancer. J Clin Oncol 26: 5705-5712, 2008.

11. Trojan J, Mineur L, Tomášek J, Rouleau E, Fabian P, de Maglio G, García-Alfonso P, Aprile G, Taylor A, Kafatos G, et al: Panitumumab use in metastatic colorectal cancer and patterns of KRAS testing: Results from a Europe-wide physician survey and medical records review. PLoS One 10: e0140717, 2015.

12. Hu J, Yan WY, Xie L, Cheng L, Yang M, Li L, Shi J, Liu BR and Qian XP: Coexistence of MSI with KRAS mutation is associated with worse prognosis in colorectal cancer. Medicine (Baltimore) 95: e5649, 2016.

13. Sideris M and Papagrigoriadis S: Molecular biomarkers and classification models in the evaluation of the prognosis of colorectal cancer. Anticancer Res 34: 2061-2068, 2014.
14. Slik K, Kurki S, Korpela T, Carpén O, Korkeila E and Sundström J: Ezrin expression combined with MSI status in prognostication of stage II colorectal cancer. PLoS One 12: e0185436, 2017.

15. Ciardiello $\mathrm{F}$ and Tortora G: EGFR antagonists in cancer treatment. N Engl J Med 358: 1160-1174, 2008.

16. Neumann J, Zeindl-Eberhart E, Kirchner T and Jung A Frequency and type of KRAS mutations in routine diagnostic analysis of metastatic colorectal cancer. Pathol Res Pract 205 858-862, 2009.

17. Shemirani AI, Haghighi MM, Milanizadeh S, Taleghani MY, Fatemi SR, Damavand B, Akbari Z and Zali MR: The role of kras mutations and MSI status in diagnosis of colorectal cancer. Gastroenterol Hepatol Bed Bench 4: 70-75, 2011.

18. Vilar E and Gruber SB: Microsatellite instability in colorectal cancer-the stable evidence. Nat Rev Clin Oncol 7: 153-162, 2010.

19. Philip P, Ernst P and Wantzin GL: Karyotypes in infectious mononucleosis. Scand J Haematol 15: 201-206, 1975.

20. Kambara T, Simms LA, Whitehall VL, Spring KJ, Wynter CV, Walsh MD, Barker MA, Arnold S, McGivern A, Matsubara N, et al: BRAF mutation is associated with DNA methylation in serrated polyps and cancers of the colorectum. Gut 53: 1137-1144, 2004.

21. Ye JX, Liu Y, Qin Y, Zhong HH, Yi WN and Shi XY: KRAS and BRAF gene mutations and DNA mismatch repair status in Chinese colorectal carcinoma patients. World J Gastroenterol 21: 1595-1605, 2015.

22. Omidifar N, Geramizadeh B and Mirzai M: K-ras mutation in colorectal cancer, a report from Southern Iran. Iran J Med Sci 40: 454-460, 2015

23. Fujiyoshi K, Yamamoto G, Takahashi A, Arai Y, Yamada M, Kakuta M, Yamaguchi K, Akagi Y, Nishimura Y, Sakamoto $\mathrm{H}$, et al: High concordance rate of KRAS/BRAF mutations and MSI-H between primary colorectal cancer and corresponding metastases. Oncol Rep 37: 785-792, 2017.

24. Martinetti D, Costanzo R, Kadare S, Alimehmeti M, Colarossi C, Canzonieri V, Berretta M and Memeo L: KRAS and BRAF mutational status in colon cancer from Albanian patients. Diagn Pathol 9: 187, 2014.

25. Kawazoe A, Shitara K, Fukuoka S, Kuboki Y, Bando H, Okamoto W, Kojima T, Fuse N, Yamanaka T, Doi T, et al: A retrospective observational study of clinicopathological features of KRAS, NRAS, BRAF and PIK3CA mutations in Japanese patients with metastatic colorectal cancer. BMC Cancer 15: 258, 2015.

26. Ogura T, Kakuta M, Yatsuoka T, Nishimura Y, Sakamoto H, Yamaguchi K, Tanabe M, Tanaka Y and Akagi K: Clinicopathological characteristics and prognostic impact of colorectal cancers with NRAS mutations. Oncol Rep 32: 50-56, 2014.

27. Yamane LS, Scapulatempo-Neto C, Alvarenga L, Oliveira CZ, Berardinelli GN, Almodova E, Cunha TR, Fava G, Colaiacovo W, Melani A, et al: KRAS and BRAF mutations and MSI status in precursor lesions of colorectal cancer detected by colonoscopy. Oncol Rep 32: 1419-1426, 2014.

28. Fleming M, Ravula S, Tatishchev SF and Wang HL: Colorectal carcinoma: Pathologic aspects. J Gastrointest Oncol 3: 153-173, 2012.

This work is licensed under a Creative Commons Attribution-NonCommercial-NoDerivatives 4.0 International (CC BY-NC-ND 4.0) License. 